\author{
Un Panorama de la Pastoral Universitaria para su Definición y \\ Establecimiento en el Proyecto Educativo Institucional de la USTA en \\ Colombia
}

A panorama in the university ministry for the definition and establishment of the institutional educational project of the USTA in Colombia

\author{
GRUPO DE INVESTIGACIÓN JORDÁN DE SAJONIA \\ Director: \\ Fr. ALVARO JOSÉ ARANGO RESTREPO, O.P. \\ Investigadores: \\ EDGAR ANTONIO GUARÍN RAMÍREZ \\ SONIA PATRICIA CORTÉS ZAMBRANO \\ JAVIER ALDANA ROJAS \\ JORGE MARTÍNEZ RODRÍGUEZ
}

Fecha de recepción: 26 de septiembre de 2011 Fecha de evaluación: 27 de septiembre de 2011

Fecha de aprobación: 21 de octubre de 2011

\title{
RESUMEN
}

Este trabajo presenta una revisión de lo que en teoría se entiende por Pastoral Universitaria, conforme a diversas miradas intraeclesiales, que van desde la concepción que se tiene de universidad en la tradición dominicano-tomista, 
pasando por la visión de universidad que ofrecen los documentos conciliares del Vaticano II, hasta llegar a lo que se piensa por presencia evangelizadora en la universidad, de acuerdo con los documentos pontificios que durante los dos últimos Papados, se han producido para orientar el ejercicio mismo de dicha pastoral.

\section{PALABRAS CLAVES}

Pastoral universitaria, Evangelio, Cultura, Valores Humanos, Ética.

\section{ABSTRACT}

This work presents a review of what in theory is meant by Campus Ministry, according to different looks within the Church, from the conception we have of college at Dominican-Thomistic tradition, through the vision offered by the university council documents Vatican II, to become what is thought by evangelizing presence in the university, according to papal documents that during the last two popes have been produced to guide the very exercise of this ministry.

\section{KEY WORDS}

Campus ministry, Gospel, Culture, Human Values, Ethics. 
Tipo de artículo: Reflexión Académica

\section{LA PASTORAL UNIVERSITARIA EN LA TRADICIÓN DOMINICANO TOMISTA}

El análisis de la misión de la Pastoral Universitaria debe partir de la misión universitaria católica y de la función de sus agentes: directivos, docentes, administrativos y estudiantes, éste aspecto se describe con la ayuda de autores que presentan acertadamente esta visión así:

El hombre es un ser que tiene que determinarse a sí mismo, a través del ejercicio de su libertad, en comunidad con los demás. (Schillebeeckx 1969), y en esa medida se hace responsable ante el porvenir el ejercicio de su libertad. Desde la perspectiva teológica, el hombre debe determinarse en diálogo con Dios. El hombre cristiano es responsable delante de Dios del sentido personal de su vida y del sentido que éste le da al mismo, por tanto, la libertad es una responsabilidad ante Dios en relación con el prójimo y el mundo.

La responsabilidad del intelectual católico, parte de la búsqueda del Reino de Dios, haciéndose responsable del mundo de hoy y del mañana, y en ésta 
búsqueda juega un papel preponderante la Universidad, cuya misión principal es la de formar intelectuales aptos para ejercer unas funciones, poniendo como base de su enseñanza una autentica concepción de la vida. Dentro de la perspectiva cristiana se trata de un "apostolado de la inteligencia" (Schillebeeckx 1969 p. 426).

Entonces se hace necesario analizar el papel de la Universidad Católica en el mundo, la universidad hace que la existencia humana, que se piensa a sí misma, sea reflexionada, para lo cual es indispensable la colaboración de las ciencias, en una sociedad abocada al diálogo y al pluralismo como ésta, la intercomunicación es de gran valor.

El antiguo conflicto entre iglesia $y$ fe, indujo a las universidades a constituirse en espacios antirreligiosos, dominadas en su mayoría por el anticlericalismo, y en respuesta a ello, se abren en número creciente, universidades católicas, para demostrar que los creyentes eran capaces de cultivar las ciencias objetivamente y sin prejuicios (Schillebeeckx 1969).

La universidad católica no es solo de filósofos y teólogos, que se encarguen de integrar los descubrimientos científicos en la visión de la Fe, sino que ésta es en sí misma la tarea científica de todos. 


\subsection{El ideario intelectual de Domingo de Guzmán}

Se puede afirmar que Domingo de Guzmán es uno de los santos fundadores que vio con mayor claridad, la necesidad del estudio como arma apostólica, bajo la consideración que el mismo tenía en cuanto que así como el estudio monástico, era de innegable finalidad contemplativa y cumplía siempre una gran función espiritual, tanto para el monje en su vida íntima, como en el interior del monasterio; de igual forma, el estudio catedralicio, con su carácter institucional, llevaba consigo una formación teológica de índole pastoral para el ministerio del sacerdote, convirtiéndose así en un medio fundamental para la defensa y difusión de la verdad. (Galmes \& Gomez, 1987)

Sin duda, la experiencia de la gran difusión de la herejía en Toulouse tuvo mucho que ver con este ideal, puesto que Domingo, al darse cuenta de la proliferación de la ignorancia y del error entre los habitantes de aquella región, encontró en dicha situación, el supuesto fáctico indudable, para deducir, que la propagación de la fe solo se podía lograr por la predicación y enseñanza de la verdad en todo el mundo, la cual a su vez, no se podía conseguir sin la participación activa de los centros de mayor solvencia en el estudio, para ese entonces, París y Bolonia, ciudades en las cuales no solo se encontraban grandes 
universidades, sino también, hombres de una grandeza intelectual indescriptible y necesarios para la nueva tarea de la evangelización.

Es más, la necesidad del estudio como una exigencia vital está afirmada desde la primera hora por el fundador de la Orden Dominicana y será constantemente recordada por todos los textos constitucionales y por las autoridades de la Orden a través de los siglos. Santo Domingo perteneció a una época (finales del siglo XII y primer cuarto del siglo XIII) en la que se va configurando un nuevo modelo sociocultural debido, en gran parte, a la misma evolución que llevaría a la Europa medieval del feudalismo a las comunas y que implicará, como es lógico, un cambio de mentalidad. Las cruzadas, con los nuevos horizontes culturales y comerciales que ellas abrieron; la derrota y disgregación del Sacro Imperio romano-germánico, que hizo que Europa dejara de ser una teocracia; la formación de los nuevos estados modernos, de los cuales el más representativo fue la nueva Francia de Luis IX; las influencias del Islam con sus triunfos militares y sus grandes centros de cultura, la aparición de la nueva sociedad comunal con sus corporaciones de artesanos y comerciantes, que reemplazan a los siervos de la sociedad feudal; todo esto no pudo sino determinar una nueva mentalidad. (Napole, 2009)

Una de las corporaciones más importantes y quizá la principal, era la asociación de maestros y estudiantes, con su reglamento interno, su autonomía, su derecho a intervenir en la vida pública. La Universidad se presentará, al 
comienzo, como una de tantas corporaciones pero, dado su carácter especial y puesta en el centro mismo de la ciudad, se convertirá en el eje de la misma y de toda la vida pública, con un alcance que irá más allá de los límites de una ciudad o incluso de las incipientes naciones. Cuando Santo Domingo comenzó su experiencia de predicación en el sur de Francia (1206), la Iglesia afrontaba una grave crisis escolar y el nuevo mundo comunal se estaba organizando al margen $\mathrm{y}$, con frecuencia, en una actitud de hostilidad y enemistad cada vez más exacerbada hacia la misma Iglesia. Ésta no contaba con mucha gente preparada para comprender y encauzar debidamente el nuevo tipo de ser humano y de sociedad que se estaba configurando, así como para afrontar los graves problemas que ésta planteaba a la fe cristiana y a su anuncio evangelizador.

En ese contexto, Santo Domingo dispone que las primeras fundaciones de su Orden sean en ciudades universitarias. Cinco frailes son enviados a París para fundar el famoso convento de Saint Jacques, en 1217, apenas un año después de la aprobación de la Orden por Honorio III. La finalidad de esta fundación es explicada de este modo por uno de los integrantes del grupo, Fray Juan de España, cuando más tarde declara en el proceso de canonización de Santo Domingo: "[Envió a sus frailes a París] para que estudiaran, predicaran y fundaran un convento." Donado por el maestro Juan de Barastre, profesor de la Universidad, recibieron del mismo maestro los cursos de Teología. Será habitual que los primeros dominicos ingresen a la escuela de un Maestro en Sagrada 
Teología con el fin de capacitarse para la predicación del Evangelio. En 1220 y en 1221 el Papa Honorio III describe a los dominicos de París como religiosos aplicados al estudio de la "Sacra Página", que era el modo como se llamaba a la Teología. Igualmente en Bolonia vemos a los primeros dominicos entregados al estudio, pues fueron enviados a dicha ciudad universitaria con ese objetivo. Estos frailes enviados a las universidades no son simples estudiantes sino predicadores activos. El hecho es verdaderamente manifestativo de una concepción del estudio en relación con la institución universitaria. No se trataba sólo de hacer una lectura edificante de la Biblia, ni siquiera de la meditación al estilo monástico para alimento de la piedad personal o comunitaria. La propuesta era la búsqueda y la reflexión allí donde los problemas doctrinales de la época se presentaban con toda su agudeza; se estudiaba en el ambiente en que se daba el encuentro de las disciplinas religiosas y profanas. Los hermanos no se aíslan tras las paredes del claustro; se preparan para vivir en el propio medio, abierto y agitado, donde confluían las diferentes tendencias y corrientes culturales.

Formados en las universidades y teniendo allí, desde el principio, a sus profesores, los primeros dominicos harán de sus mismos conventos, otras tantas escuelas en que se consagrarán al estudio de manera constante y metódica. Y así, la orientación inicial del estudio dominicano aparecerá con estas características: es organizado, metódico, institucional, en contacto con el medio universitario y abierto a la problemática de la actualidad. En definitiva, el problema 
de la fe, según creía Santo Domingo, tenía que abordarse con los mismos instrumentos y métodos de la cultura que estaba naciendo. Domingo quiso comprometer a sus hermanos dentro del despertar intelectual de su época y procuró situar a su Orden en relación con las nuevas condiciones sociológicas del pensamiento y los cambios culturales que ocurrían entonces. (Napole, 2009)

Aun contando con todos los riesgos de las generalizaciones, es innegable que el siglo XIII fue un siglo de una llamativa variedad sin perder la unidad, robustecida después de las luchas del Papado con el Imperio. Es una época que se distingue por sus grandes creaciones en el campo de la ciencia, del arte, y de la espiritualidad cristiana. Los mismos movimientos heréticos estimulan el espíritu creador y luchador del hombre medieval. Es un momento histórico en el que nuevos caminos abiertos a la sociedad cristiana de la Europa medieval, atraen a muchos y se llevan a cabo grandes empresas y se prepara el camino para nuevas tareas en siglos posteriores.

Dada la dimensión apologética del estudio y su importante repercusión a la hora de predicar, como fiel seguidor de las normas eclesiásticas, precisa bien que el estudio ha de ser de las ciencias sagradas. «Tanto los jóvenes como los demás estudien solamente libros teológicos», aunque no excluye echar algunas ojeadas sobre los escritos de los filósofos, referido más bien a los de los herejes. Con la 
debida autorización pueden llegarse a las ciencias profanas que se iban imponiendo, como medicina, física, ciencias naturales, etc.

Se comprende que nos hallamos ante una nueva comprensión y valoración del estudio, y por lo tanto, algo que exige normas nuevas y distintas. Como principio general es significativo que disponga que los consagrados al estudio y a la predicación, no deban recibir cargos ni responsabilidades administrativas. Al establecer como norma de conducta en los superiores la debida y conveniente aplicación de la ley de la dispensa, precisa que debe aplicarse a «todo aquello que pareciere impedir el estudio, la predicación o el provecho de las almas». Principio de grandiosa fecundidad que invita a muy serias reflexiones cuando del bien de las almas se trata.

Así pues, con un criterio tan intelectualista se jerarquizaron todos los trabajos del dominico, al punto de conceder las dispensas y privilegios necesarios para quienes oficiaban como profesores y estudiantes, obteniendo como resultado de todos estos esfuerzos, la gran organización de frailes, que con demasiado brillo aportaron al siglo XIII, uno de los más gloriosos de la iglesia. De hecho, es posible afirmar, que la causa principal del resplandor intelectual de esta centuria sin quitar nada a nadie y sin olvidar el concurso otras entidades y corporaciones, la vemos en la Orden de Predicadores, fundada y organizada por el genio español Domingo de Guzmán, puesto que sin su intervención eficiente constante y universal en 
todas las ramas del saber, el siglo XII, jamás habría sido, el siglo XIII que la humanidad conoció. (Carro, 1946)

Por todo lo anterior, debe admitirse que desde los orígenes, y por su propia configuración, la Orden Dominicana aparece como una Orden universitaria (Díaz Camacho, 1993), puesto que su orientación inicial del estudio dominicano aparece de manera organizada, metódica, institucional, en contacto con el medio universitario y abierto a la problemática de la actualidad, al punto que busca y reflexiona donde los problemas doctrinales de la época se presentan en toda su agudeza. De este modo, el predicador no solo estudiaba en el ambiente en que se daba el encuentro de las disciplinas religiosas y profanas, libre del aislamiento tras las paredes del claustro, sino que también se preparaba para las luchas del espíritu en el propio medio, abierto y agitado, donde confluían las diferentes tendencias y corrientes culturales. (Pinto de Oliveira, 1983)

\subsection{Idea Dominicana de Universidad}

Los dominicos, restauran el primer claustro universitario de Colombia, clausurado en 1861, en respuesta a su misión y servicio evangelizador, cultural y social. La restauración inicia con la idea de presentar programas de estudio de

actualidad, que respondan a los problemas de hoy, y que brinde a los jóvenes la 
facilidad y los medios de separarse para actuar en el medio ambiente y a las diversas circunstancias.

El estudio universitario se ciñe a las reglas del estudio dominicano, organizado, institucional, metódico, abierto a la problemática actual. Fueron los Dominicos quienes abordaron los problemas planteados por la moral, el derecho y la teología, y se presentan como comunicadores de la verdad del evangelio, de tal manera que el desarrollo cultural conduzca a un conocimiento más claro de la vocación humana e impulsa a las mentes a una comprensión más elevada de la fe.

Se precisa que el principio de autonomía, no debe conducir a la indiferencia y al escepticismo, ante lo religiosos, social y cultural. La libertad académica no demerita la ética del saber. Bebe por tanto la universidad católica favorecer los espacios que garanticen el equilibrio de la experiencia sensible y la objetividad en el proceso cognoscitivo, alejando el "peligro del pensamiento subjetivo que puede conducir al agnosticismo" (Barrado O.P. 1993 p. 585).

La llamada dimensión humanística de la universidad, va con el destino del hombre y el sentido de la existencia y de la sociedad, lo cual constituye una característica del quehacer universitario. El cumplimiento de la función humanística, que ayuda a descubrir el sentido de la vida hombre y sus proyectos, 
haciendo inteligible la realidad en su propia perspectiva antropológica, histórica y teleológica, es el verdadero sentido de la catolicidad de la universidad, evolucionada y dinámica, conciliando la secularidad del mundo y la autonomía de las realidades mundanas con las exigencias radicales del evangelio.

En éste sentido la universidad requiere profesores con compromiso de fe, que sepan "establecer un vínculo entre su propia perspectiva científica y la búsqueda del sentido de las cosas y de la realidad humana, relacionando adecuadamente su especialidad con la totalidad de lo real y de la existencia humana" (Barrado O.P. 1993 p. 586).

La universidad desde la perspectiva tomista- dominicana debe intensificar y fortalecer los niveles de calidad y competencias profesional y ética de todos sus integrantes, para que aprendan a razonar con rigor, a obrar con rectitud y a servir mejor a la sociedad.

Es por ello que deben buscarse nuevos acercamientos entre el saber científico y los valores, con el fin de promover la integridad humana y social, por ello los métodos educativos deben proporcionar los medios científicos válidos para que quienes en ella se formen, sean capaces de interpretar al hombre en relación con su medio y de conformidad con las exigencias de su tiempo. 


\subsection{La formación en la vida universitaria}

Los estatutos de la Universidad Santo Tomás, presentan dentro de sus fines, el examen de los problemas fundamentales de nuestro tiempo, a la luz de las enseñanzas de Santo Tomás, que tienen unión íntima con las verdades evangélicas.

El desarrollo de nuestros tiempos obliga a pensar en términos de solidaridad unión de gremios y grupos profesionales, para impulsar el desarrollo intelectual unido en sabiduría a los valores, sin descuidar uno solo de los problemas de nuestro tiempo.

Santo Tomás captó a fondo la función de la universidad en la promoción cultural y se sintió arquitecto de la misma. (Fernández 1993 p. 29). Es una idea viva del Santo, la necesidad de edificar comunicando la palabra de Dios, hablando de Dios, ayudado por las tres tareas: la lectio, la predicatio y la disputatio, allí se hace real el ideal de la universidad.

Se insiste en que la universidad es el lugar adecuado para el desarrollo de la humanidad del hombre, dirigido por su condición de inteligente, racional, 
designado con la palabra verdad, el ser humano ha nacido para la verdad, su tarea es apropiarse de la verdad de manera intencional, y en su condición de hombre libre, se siente interpelado para dejarse modelar y transformar por ella.

La vida de la universidad debe ser el ejercicio del ser racional, en su búsqueda y comprensión de la verdad y sobre ellos establece Santo Tomás los quehaceres específicos e ineludibles. (Fernández 1993).

\subsection{Tareas de la Universidad}

La primera tarea de la universidad consiste en situarse en la cima del proceso cultural, estar a la altura de los tiempos. Parte de la conciencia de la unidad del género humano y del reconocimiento de la importancia de la tradición cultural y memoria del pasado. Una de las tareas de la universidad consiste en ser la memoria viviente de la tradición cultural, la racionalidad humana exige tarea de constante colaboración cultural en armonía con el pasado del hombre.

La segunda tarea, consiste en la transmisión de la verdad en el presente. La verdad más alta pertenece a la revelación y se acoge por la fe (Fernández 1993p. 36), por tanto la universidad es el lugar de diálogo y de investigación que conduzca apropiadamente a un acercamiento a la verdad. La universidad debe ser un foro de presentación y transmisión de la verdad, un lugar de encuentro de los 
hombres en las diferentes escuelas y visiones de las cosas. La verdad no se impone desde la autoridad sino por su propia fuerza, y pone a prueba cada día al profesor.

La tercera tarea orientada hacia el futuro, no se desliga del hecho que todo conocimiento parte de la experiencia y se condiciona por la corporeidad y los sentidos. El hombre ha nacido para la felicidad, la cual consiste en la posesión gozosa de la verdad. La verdad hace al hombre feliz, el error lo hace desgraciado. (Fernández 1993p. 39). La universidad es el lugar donde se forja integralmente el hombre y donde se hace posible el futuro racional de la humanidad.

\subsection{Responsabilidad del maestro - profesor en la universidad}

Compete al maestro conducir a los alumnos a la madurez humana, dirigirlo hacia la plenitud humana, el maestro es un guía en el camino de lo humano, en la conquista de la perfección a la que se siente llamado todo hombre. El maestro es un auxiliar, un instrumento a su servicio, la verdad parte de la adecuación de las cosas y de la inteligencia, adecuación de todo cuanto existe a la inteligencia creadora de Dios por medio del Verbo.

Conocer es conocer el ser, abrirse a la realidad, asimilar las formas de las cosas de modo racional, conocer es ver las cosas a la luz de la mente y de los 
principios. El maestro como auxiliar, supone un ejercicio de diálogo, comunicación, tutoría y seguimiento de procesos de aprendizaje. El maestro promueve capacidades que ya existen en el alumno, que tiene por naturaleza.

El desarrollo de la inteligencia prepara al hombre a juzgar y a ordenar, donde hay orden hay inteligencia, donde hay juicio adecuado hay verdad. El maestro debe despertar en los estudiantes la dimensión integral del hombre y lo hace a partir del desarrollo de las virtudes morales que hacen bueno al hombre. No hay medio más eficiente para promover el bien que el ejemplo, los malos ejemplos corrompen las buenas costumbres y los buenos incitan a seguirlos, el profesor debe ser un modelo.

\subsection{El Profesional Universitario}

De los profesionales depende la marcha de la sociedad, el ejercicio profesional, requiere un hombre formado en la virtud, un hombre bueno.

Se requiere que la libertad sea el principio de todo acto humano, pero se exige que el acto humano esté regulado para que se dirija al fin debido y es precisamente que el orden racional al fin resulta la moralidad, lo justo y lo injusto, lo bueno y lo malo. 
El rol del profesor en la orientación de la libertad, se construye desde el ejemplo y la doctrina. Se busca fortalecer al ser humano en su autonomía, integralidad y dignidad, desde la formación humana y cristiana, desde sólidos fundamentos en la verdad y el bien.

\section{LAS DIRECTRICES CONCILIARES QUE ILUMINAN LA ACCIÓN PASTORAL AL INTERIOR DE LA UNIVERSIDAD}

También en el Concilio Vaticano II encontramos algunas luces sobre lo que implica la labor pastoral dentro de la universidad. Si bien es cierto que en los textos conciliares no se encuentra un documento que haga referencia directa a la pastoral universitaria, no lo es menos que dicho acontecimiento de la Iglesia universal, tuvo una especial inclinación hacia la pastoral y, por eso, dedicó una Constitución entera a analizar y desarrollar el tema: la Constitución Gaudium et Spes. De la mano de dicho documento, se pueden inferir algunas consecuencias importantes para el desarrollo de la pastoral universitaria de la Universidad Santo Tomás. Antes de emprender esta tarea analítica, conviene recordar -a manera de premisa- lo consignado por René Latourelle en este corto texto: "Lo hemos dicho ya: el Vaticano II es un gran signo dirigido a los hombres de nuestro tiempo. Hemos recibido el signo, pero, ¿seremos capaces de leerlo?... El signo del concilio es contemporáneo a las amenazas de destrucción de la humanidad. Por eso, 
proponiendo a Cristo como Vida, a la Iglesia como sacramento de vida y de salvación universal, el concilio puede ayudar a los hombres a triunfar sobre la muerte, a condición de lo encarnemos en nuestras vidas. Pero sobre todo, el concilio debe gestar santos, para testimoniar su fecundidad; el mundo los espera. Si ellos no se hacen visibles, los hombres vivirán en densa niebla y morirán ateridos" (1989, p. 16)

Con este espíritu, lo primero que se puede extractar de la enseñanza conciliar respecto de la pastoral universitaria, es la imposibilidad de dar respuestas adecuadas a los jóvenes universitarios de hoy, si no es acercándose a ellos y atendiendo a sus "perennes interrogantes sobre el sentido de la vida presente y de la vida futura, y sobre la mutua relación de ambas" (Concilio Vaticano Segundo, G.S. N 4). Esta invitación adquiere especiales dimensiones, en el momento en que la reflexión conciliar se vuelca sobre las ineluctables relaciones entre fe y cultura. El Concilio hace un especial llamado a buscar las mejores formas para hacer llegar el mensaje del evangelio “... porque una cosa es el depósito mismo de la fe, o sea, sus verdades, y otra cosa es el modo de formularlas, conservando el mismo sentido y el mismo significado" (Ibídem, $\mathrm{N}^{\circ}$ 62, par. 2). Lo interesante, para efectos de la pastoral de la Universidad Santo Tomás, es la invitación a hacer de la pastoral un camino para asegurar la armonía entre cultura y cristianismo, esto es, hacer del mensaje de Cristo una realidad encarnada en la historia y en el lenguaje de los hombres. 
En esta línea, es especialmente iluminador el discurso de inauguración del Concilio, proferido por el Papa Juan XXIII. El Sumo Pontíficie refiere a algo que, hoy en día, tiene especial relevancia para determinar con precisión el sentido y alcance de la pastoral universitaria. Decía: "Una cosa es lo sustancial de la antigua doctrina del depositum fidei y otra su formulación y su ropaje: y es esto lo que hay que tener en cuenta, con la paciencia necesaria, sopesando debidamente las formas y las proposiciones de una enseñanza con carácter, sobre todo, pastoral" (1962). La pastoral universitaria debe, pues, ser especialmente cuidadosa de ese depósito de la fe, a la vez que tiene que buscar las mejores formas para hacer llegar dicho depósito. Aparecen aquí el objeto y el método: dos elementos fundamentales que hay que tener en cuenta cuando se trata de reflexionar sobre la pastoral en el medio universitario. Es el llamado "aggiornamiento" que se abrió paso con éxito en el Concilio y que muestra la apuesta pastoral de la Iglesia: esforzarse por renovar su comprensión del mundo actual -de los jóvenes de nuestra universidad-, leyendo sus necesidades, sus sufrimientos, anhelos y esperanzas, e iluminarlas con el mensaje del Evangelio que está siempre vivo.

Otra enseñanza especialmente importante que trae el Concilio, es que no es posible una pastoral universitaria católica, que no sea Cristocéntrica. Constantemente el concilio hace referencia a Cristo como la respuesta verdadera al misterio del hombre: él tiene la capacidad de dar sentido al hombre y a sus problemas (Cfr. Concilio Vaticano II. Gaudium et spes. №22). Eso significa que el 
éxito de cualquier actividad pastoral que se adelante al interior de la universidad, dependerá de su vinculación con la persona y el mensaje de Cristo, fuente de toda actividad pastoral (Cfr. Concilio Vaticano II. Lumen Gentium, № 34). De allí se deriva la norma que ha de regir toda actividad pastoral en la Iglesia: la fecundidad del trabajo pastoral depende de la unión vital que se tenga con Cristo (Cfr. Concilio Vaticano II. Decreto Apostolicam actuositatem $\mathrm{N}^{\circ} 4$ ). Por eso, la pastoral universitaria tiene que ayudar a que los jóvenes conozcan a Cristo; allí es importante tarea el buscar los mejores medios. Ahora bien, gracias a la acción del Espíritu Santo que derrama sus carismas en cada cristiano, esa unión con Cristo se hace fructífera en cada momento y circunstancia de la historia. De allí la importancia de involucrar a los jóvenes en la labor pastoral que se realiza en la universidad, aprovechando al máximo sus dones y carismas; sin tenerles en cuenta, la misión de la Iglesia se empobrece y se hace estéril.

Otro aspecto fundamental dentro de la pastoral, es el testimonio de vida (Cfr. Concilio Vaticano II. Gaudium et Spes. N 43). Ese "ser verdaderos testigos" de Cristo, tiene una especial relevancia al interior de comunidades eclesiales pequeñas, como lo es la universidad. Ahora bien, dado que los jóvenes que llegan a la Universidad Santo Tomás, aún se encuentran en esa etapa de formación en la que aprenden mucho del ejemplo de los directivos y docentes, este llamado del Concilio ha de encontrar especial eco en ellos. Eso implica un trabajo con el cuerpo directivo y docente, que les lleve a concientizarse de su papel en esa tarea 
pastoral que es fundamental dentro de la Universidad. Sin duda, directivos y docentes que no tengan claro cuál es la institución en la que se encuentran y cuál es su papel dentro de ella -el cual pasa por ser fuente inagotable de las virtudes de que tan necesitado anda el mundo de hoy-, no pueden contribuir a la realización de esa tarea evangelizadora que le compete a la tomista.

Lo anterior, está en plena armonía con la invitación conciliar a la participación del laico en la vida pastoral de la Iglesia. Tarea que no es sencilla y que requiere especial cuidado: "a los laicos..., por razón de su condición y misión, les atañen particularmente ciertas cosas, cuyos fundamentos han de ser considerados con mayor cuidado a causa de la especiales circunstancias de nuestro tiempo" (Concilio Vaticano II. Lumen Gentium, N³0). La pastoral universitaria debe, en ese sentido, ser un campo de formación de líderes cristianos. Invita a los laicos -a los docentes y a los estudiantes-, a que "compaginen los conocimientos de las nuevas ciencias y doctrinas y de los más recientes descubrimientos, con la moral cristiana (que no es otra que la moral del amor fraterno), para que la cultura religiosa y la rectitud del espíritu vayan en ellos al mismo paso que el conocimientos de las ciencias... así se capacitarán para examinar e interpretar todas las cosas con íntegro sentido cristiano". (Concilio Vaticano II. Gaudium et Spes. №62). 
De otra parte, el Concilio muestra a una Iglesia que en su labor pastoral, ha de ser consciente de la libertad del hombre y de sus derechos personales; habla de la libre elección del creyente al momento de adherir a la fe. Así mismo, hace una invitación a no tener miedo frente al espíritu crítico que caracteriza al joven de hoy: dicho espíritu puede poner en peligro una fe superficial, pero puede de igual modo purificar el espíritu religioso: "el espíritu crítico... exige cada más una adhesión verdaderamente personal y operante a la fe, lo cual hace que muchos alcancen un sentido más vivo de lo divino" (Ibídem, $\mathrm{N}^{\circ} 7$ ).

Finalmente, los Obispos insisten en la importancia de la Escritura en la vida pastoral de la Iglesia. El esfuerzo pastoral tiene que estar iluminado por una comprensión cada día más profunda de las Sagradas Escrituras a fin de alimentarse, sin tregua, de la palabra divina. Allí, la ayuda del Espíritu Santo, vivo y actuante en la Iglesia, es fundamental. Es pues importante, dentro de la acción pastoral universitaria, buscar diversos medios para hacer que la palabra de Dios llegue hasta los jóvenes; no se puede olvidar que esa palabra es más cortante que espada de doble filo, tal como lo dice la misma Escritura. Como bien lo afirma Maurice Gilbert (1989), "sabemos cómo, en todo el mundo, se ha incrementado la dimensión bíblica de la pastoral... la competencia de los animadores de la pastroal bíblica se ha acrecentado considerablemente" (p. 232). Aunado a ello, la labor pastoral universitaria no puede dejar de lado la importancia que tiene el potenciar la activa participación en la liturgia. El Concilio resalta, como elemento 
fundamental de la vida pastoral, la participación en la liturgia de manera consciente y personal: “... que se lleve a todos los fieles a aquella participación plena, consciente y activa en las celebraciones litúrgicas, que exige la naturaleza misma de la liturgia" (Concilio Vaticano II. Declaración Sacrosanctum Concilium N¹4).

\section{UN PANORAMA DE LA PASTORAL UNIVERSITARIA EN DIFERENTES DOCUMENTOS ECLESIALES}

\subsection{En la Conferencia Episcopal de Colombia y la Arquidiócesis de Bogotá.}

La Pastoral Universitaria en la Arquidiócesis de Bogotá hay que entenderla dentro del marco de la comprensión de la Iglesia Universal. Esta se enmarca dentro de lo que se llama Pastoral para la Cultura (Consejo Pontificio para la Cultura, 1999). De aquí que en la Conferencia Episcopal Colombiana desde 1968 se incorpore a las tareas de la Iglesia la Pastoral para la Educación y en 2003, en el Plan Global de Pastoral se le designe a la Comisión Episcopal Pastoral para la evangelización de la cultura y la educación (Departamento Pastoral para la Evangelización de la Cultura y la Educación, Conferencia Episcopal de Colombia., 
2005), donde se trabaja la Pastoral Universitaria y todo lo que implica la relación de la Iglesia con las universidades e instituciones de Educación Superior.

La CEC organiza su actividad con programas de acción. El Programa 78 se refiere a la Pastoral Universitaria (Departamento Pastoral para la Evangelización de la Cultura y la Educación, Conferencia Episcopal de Colombia, 2005) y en su objetivo y metas podemos ver las tareas que comprenden esta pastoral, a saber:

OBJETIVO:

Presentar a Jesucristo con su verdadero rostro y proponer el encuentro con El, para que la formación universitaria proponga a los universitarios una eficiente evangelización de su inteligencia, de su conciencia y de su discernimiento, de tal forma que la Universidad sea un espacio para descubrir al Padre de Jesús y un ámbito para crecer en la fe.

\section{METAS Y LÍNEAS DE ACCIÓN}

1. Asesorar e iluminar la tarea de los Señores Obispos y de los Delegados Diocesanos de Pastoral Universitaria en la proyección y planificación 
de los distintos procesos de actualización de la pastoral universitaria ante los paradigmas y las culturas de las nuevas generaciones universitarias.

2. Proponer encuentros que fomenten el conocimiento e intercambio de vivencias pastorales en las universidades para proyectar la tarea evangelizadora universitaria desde las experiencias vividas por otros agentes de pastoral en la universidad.

3. Realizar Seminarios y Talleres que presenten estudios e investigaciones sobre propuestas para una pastoral universitaria actualizada y centrada en las culturas emergentes de los jóvenes universitarios.

4. Realizar congresos anuales nacionales y regionales de capellanes, delegados diocesanos de pastoral universitaria, vice rectorías de pastoral universitaria y de bienestar institucional, para estudiar y analizar los principales fenómenos de sociedad y de ingerencia política, cultural, religiosa y científica que nacen en las universidades y su incidencia en la pastoral universitaria.

5. Convocar a los Rectores de las Universidades en especial de las Católicas y de inspiración cristiana, así como a los Decanos y Docentes de las facultades de Educación, Psicología, Antropología, Sociología, Filosofía, Teología, Ciencias Religiosas, Ciencias Políticas y afines, para que junto con los 
responsables de la acción evangelizadora de dichas instituciones, compartan experiencias y propongan acciones conjuntas sobre el humanismo cristiano.

6. Proponer de manera permanente instrumentos de formación que les sirvan a los Capellanes y demás responsables de la pastoral universitaria para la preparación y organización de eventos internos y locales.

7. Acoger las invitaciones que el CELAM proponga para los encuentros de pastoral universitaria dada la riqueza que ofrecen y mantener comunicación e intercambio con organismos eclesiales como la FIUC y laicales como ASCUN.

Como podemos ver la visión de la CEC de la Pastoral Universitaria está en la línea de la evangelización de la cultura. En el Documento final de la Asamblea Plenaria del Consejo Pontificio para la Cultura ¿Dónde está tu dios? La fe cristiana ante la increencia religiosa (Consejo Pontificio para la Cultura, 2004), segunda parte, sobre las proposiciones concretas de la instrucción religiosa y la iniciación cristiana, en lo que se refiere a las instituciones educativas, se dice:

La Iglesia asegura su presencia a través de una pastoral universitaria, que se distingue de la simple pastoral juvenil. La pastoral universitaria apunta principalmente a la evangelización de la inteligencia, la creación de nuevas 
síntesis entre la fe y la cultura y se dirige prioritariamente a los profesores y docentes, para disponer de católicos bien formados.

En los seminarios y facultades de teología, la filosofía y la teología fundamental tienen una importancia particular como disciplinas de diálogo con la cultura moderna. Crece la necesidad de diseñar nuevos cursos y programas en el diálogo entre la ciencia y la fe.

\subsection{En el Consejo Pontificio para la Cultura, según el documento “¿Dónde está tu Dios?"}

Desde el mismo Concilio Vaticano II la iglesia se ha venido entrando en un acelerado y profundo proceso de cambio. Este obedece al surgimiento de nuevas realidades humanas que han puesto en crisis a los destinatarios de las verdades eternas que Dios ha querido manifestar a los hombres de todos los pueblos. Las gentes de la antigua cristiandad creían y practicaban su fe. Las manifestaciones de indiferencia o desidia ante la proclamación del mensaje cristiano no eran muy frecuentes y se consideraban normales cuando provenían de parte de los no creyentes por causas ideológicas o por las diferencias geográficas que habían postulado otras formas de encuentro con el absoluto como el islamismo, budismo, hinduismo, animismo y en general cualquier otra forma de encuentro personal y 
comunitario del hombre con Dios y de Dios con el hombre, desde una perspectiva distinta la tradición judeo cristiana.

Así las cosas, la cristiandad estimaba lejanas las amenazas de la increencia que seguramente provendría de los paganos, ateos y no cristianos. Pero no fue así, al interior de la iglesia la feligresía entraría en un serio proceso de abandono de las prácticas cristianas no de manera contestaría al modo de la reforma luterana, sino de forma silenciosa. A ese tipo de neopaganismo cristiano se referirá el Consejo Pontificio para la cultura en un documento del año 2004 denominado “¿Dónde está tu Dios?, la fe cristina ante la increencia religiosa”. Precisamente la línea inicial del documento abre con la siguiente cita que deja entrever cuál será la intencionalidad del documento en los siguientes términos: "La fe cristiana, al alba del nuevo milenio, se ve confrontada con el desafío de la increencia y de la indiferencia religiosa". (Consejo Pontificio para la Cultura, 2004, pág. 1).

Los antecedentes sobre el abordaje de esta problemática aparecen en el año 1965 con la creación de la Secretaria para los no creyentes, luego fue trabajado por el Consejo Pontifico para la Cultura y posteriormente; seria tema del Consejo Pontificio para el Dialogo con los no creyentes que se fusionarían en un solo consejo que según la carta apostólica Inde a Pontificatus, le atribuye la misión del: "estudio del problema de la no creencia y la indiferencia religiosa presente, 
bajo diferentes formas, en los diversos ambientes culturales, investigado sus causas y consecuencias por lo que atañe a la Fe cristiana" (Pablo II, 1993, pág. 1)

Ahora bien, al interior de la pastoral universitaria conviene tener presente el diagnóstico adelantado por el consejo so pena de incurrir en un error de principio que llevaría a tratar de forma desprevenida y ligera el tema al interior de la educación superior para lo cual en el año 2004 el Consejo Pontificio para la Cultura trabajo sobre dos preguntas clave: ¿Cómo establecer al interior de las culturas los puntos de anclaje para la transmisión del evangelio? y en segundo lugar ¿qué vías privilegiar para llevar la buena noticia de Cristo a los no creyentes, a los mal creyentes y a los indiferentes de nuestro tiempo? Precisamente porque el diagnóstico muestra que la cristiandad del siglo XXI se enfrenta al desafió de una cultura de la increencia y la indiferencia religiosa que ha traído hasta nosotros un mundo desencantado y pragmático.

El diagnostico que hace la iglesia reconoce que el hombre ha pasado por varias etapas en el desarrollo de su historia con relación a la trascendencia resumida en cuatro momentos: "homo faber, el homo sapiens y el homo religiosus - el homo indifferens" (Consejo Pontificio para la Cultura, 2004, pág. 3). El homo indifferens busca lo espiritual sin: "referencia a un Dios personal sin adhesión a un cuerpo de doctrina y sin pertenencia a una comunidad de fe, vivificada por la celebración de los misterios" (Consejo Pontificio para la Cultura, 
2004). Se trata de un retorno a lo sagrado en una perspectiva individual, autónoma y guiada por la subjetividad. Nos presenta el retrato de un cristiano que se dice creyente; sin adherirse al mensaje cristiano, que trasmite la iglesia, es decir, jcreer sin pertenecer! en una búsqueda espiritual más que religiosa.

El Consejo Pontificio para la cultura considera que las nuevas formas de increencia religiosa se relacionan con un fenómeno que está en lo más profundo de la cultura en parte producto de pretensión totalizante de la ciencia moderna, de la exaltación del hombre como centro del universo, del escándalo que produce la existencia del mal en medio del mundo, el antitestimonio de la iglesia, la secularización que impide la transmisión de la fe, la pérdida de protagonismo de la educación católica y la ausencia de profesores sin una verdadera formación y motivación cristiana. Todo ello ha llevado a la emergencia de un Dios sin características personas aunado a la fascinación que produce en occidente las denominadas religiones orientales.

Ante este panorama la misión de la iglesia consiste en asegurar al interior de la cultura la transmisión de la fe en Cristo, en razón del mandato misionero establecido en las sagradas escrituras del Nuevo Testamento, a todos los miembros de la iglesia "Es una misión transversal, que afecta conjuntamente a la catequesis y la enseñanza, la liturgia y la actividad pastoral ordinaria, las familias y las parroquias, los seminarios y las universidades" (Consejo Pontificio para la 
Cultura, 2004, pág. 16). El fundamento y la perseverancia para cumplir esta misión radica en la oración, los sacramentos y el acatamiento del llamado a la santidad de todos los cristianos como elemento facilitador para el dialogo con los no creyentes sin descontar el acercamiento antropológico centrado en la persona humana elemento común entre creyentes y no creyentes compartiendo la existencia, la vida social, y sobre todo desarrollando una apologética renovada que permita dar razón de la fe en momentos de increencia religiosa.

Corresponde a esta nueva evangelización de la cultura, la familia, fomentar la instrucción religiosa, el desarrollo de la sensibilidad estética como medio para lograr el encuentro con el Dios personal de la fe cristiana y sobre todo generar un nuevo lenguaje para comunicar el evangelio por medio de la razón y el asentimiento en todos los niveles de la vida social incluidos colegios, universidades, lugares públicos y todo lugar de la vida cultural que permita el dialogo con los que creen y no practican, o simplemente no les interesa creer. El mecanismo no podrá ser otro que el propuesto por el maestro y se resume en la vía del amor.

\subsection{En el Consejo Pontificio para la Cultura, según el documento "Presencia de la Iglesia en la Universidad y en la Cultura Universitaria”}


La Universidad, según el Consejo Pontificio para la Cultura (Consejo Pontificio para la Cultura, 1994), es de gran importancia porque en ella "se juegan cuestiones vitales, profundas transformaciones culturales, de consecuencias desconcertantes, suscitan nuevos desafíos" (nota preliminar del documento). En esta parte inicial, se dice que el motivo del documento, en su momento, fue la de suscitar la reflexión para una pastoral renovada.

El texto cita la Carta de Institución del Consejo Pontificio para la Cultura, de Juan Pablo II (20 de mayo de 1982), donde dice que "la síntesis entre cultura y fe no es sólo una exigencia de la cultura, sino también de la fe... Una fe que no se hace cultura es una fe que no es plenamente acogida, enteramente pensada 0 fielmente vivida". De aquí podemos afirmar que la Universidad tiene la gran responsabilidad de crear cultura; una cultura que esté imbuida de los valores evangélicos y que verificará la calidad de la fe. Ya el papa Pablo VI (PabloVI, 1975) en textos anteriores afirma que la evangelización es importante en la relación con la cultura, sin poder dejar de ser ajena a ella; y los documentos de las conferencias generales del episcopado latinoamericano dirán que la evangelización culmina en la creación de una cultura evangélica, y en esta tarea la Universidad tiene un papel protagónico, dice el presente texto. Termina la nota preliminar mostrando la misión que tiene la Pastoral Universitaria y cada uno de los miembros de la Iglesia; a saber: 
La fe que la Iglesia anuncia es una fides quaerens intellectum, que debe necesariamente impregnar la inteligencia del hombre y su corazón, ser enseñada para ser vivida. La presencia eclesial no puede, pues, limitarse a una intervención cultural y científica. Tiene que ofrecer la posibilidad efectiva de un encuentro con Jesucristo.

Concretamente, la presencia y la misión de la Iglesia en la cultura universitaria revisten formas diversas y complementarias. Primeramente está la tarea de apoyar a los católicos comprometidos en la vida de la Universidad como profesores, estudiantes, investigadores o colaboradores. La Iglesia se preocupa luego por el anuncio del Evangelio a todos los que en el interior de la Universidad no lo conocen todavía y están dispuestos a acogerlo libremente. Su acción se traduce también en diálogo y colaboración sincera con todos aquellos miembros de la comunidad universitaria que estén interesados por la promoción cultural del hombre y el desarrollo cultural de los pueblos.

Perspectiva semejante pide a los agentes de la pastoral universitaria entender la Universidad como un ambiente específico con problemas propios. El éxito de su empeño dependerá, en efecto, en buena medida, de las relaciones que con él establezcan, relaciones que, a veces, se encuentran en estado embrional. De hecho, la pastoral universitaria queda frecuentemente en los márgenes de la pastoral ordinaria. Por ello se hace necesario que toda la comunidad cristiana 
tome conciencia de su responsabilidad pastoral en relación con el ámbito universitario.

Y después de hacer un largo recorrido sobre la situación de la Universidad a finales del siglo pasado, en la primera parte, se desarrolla la segunda abordando el tema de la presencia de la Iglesia en la Universidad y en la Cultura Universitaria (desde las estructuras institucionales, el papel de la Universidad Católica, creación de instancias diocesanas en diálogo con las universidades). Se desarrollan en la tercera parte una serie de sugerencias y propuestas pastorales (para las iglesias locales, que apoyen a las universidades con sacerdotes y agentes laicos de pastoral; el desarrollo de una pastoral con maestros).

Se concluye retomando un texto de Juan Pablo II de la Exhortación Apostólica post-sinodal «Christifideles Laici », sobre la vocación y misión de los laicos en la Iglesia y en el mundo, en el número 44: (JuanPabloll, 1988)

«... la Iglesia es plenamente consciente de la urgencia pastoral de reservar a la cultura una especialísima atención. Por eso la Iglesia pide que los fieles laicos estén presentes, con la insignia de la valentía y de la creatividad intelectual, en los puestos privilegiados de la cultura, como son el mundo de la escuela y de la universidad, los ambientes de investigación científica y técnica, los lugares de la creación artística y de la reflexión humanista. Tal presencia está destinada no sólo 
al reconocimiento y a la eventual purificación de los elementos de la cultura existente críticamente ponderados, sino también a su elevación mediante las riquezas originales del Evangelio y de la fe cristiana ».

\subsection{En la Constitución Apostólica Ex Corde Ecclesia de S.S. Juan Pablo II "Sobre las universidades católicas"}

La universidad católica se dedica a la búsqueda de todos los aspectos de la verdad pero sobre todo a búsqueda de la verdad suprema que es Dios. El contexto de la búsqueda es un dialogo continuo entre fe y cultura, explorando la doble riqueza que otorga la revelación y la naturaleza en un ambiente cristiano que le permita al hombre alcanzar la medida plena de su humanidad por lo que la universidad católica ejerce de mediadora entre el mensaje salvífico y la multiplicidad de campos del saber. El papel de la iglesia al interior de la universidad católica se relaciona con el ministerio de dar sentido a través de la promoción de una cultura superior donde los estudiantes tengan la capacidad de dar testimonio de fe ante sí mismos, la sociedad y el mundo. La razón de ser de la universidad cristina se expresa en su naturaleza de comunidad académica empeñada en el desarrollo de la dignidad humana que garantice de forma institucional una presencia cristina en el mundo universitario frente a los grandes problemas de la sociedad. 
Ahora bien, le corresponde la universidad cristiana el cuidado, de la ovejas del rebaño bajo su responsabilidad y protección: por lo que la actividad pastoral debe estar orientada en una reflexión continua a la luz de la fe, fidelidad al mensaje cristiano, pero sobre todo de lograr el objetivo ayudar al hombre universitaria a darle sentido a la vida. De otra parte, la búsqueda de sentido exige en el trabajo pastoral la participación viva de la iglesia que incluye a los docentes universitarios, estudiantes, administrativos, laicos, religiosos y religiosas.

La Pastoral Universitaria es entendida como "aquella actividad de la Universidad que ofrece a los miembros de la Comunidad la ocasión de coordinar el estudio académico y las actividades para-académicas con los principios religiosos y morales, integrando de esta manera la vida con la fe" (Ex Corde Eclesiae, 1990). A la pastoral universitaria le corresponde la tarea de promover el carácter católico de la universidad, mediante el testimonio de la fe, en tres momentos el primero en la actividad normal, el de la reflexión; pero sobre todo en la oración. En consecuencia la Constitución Apostólica Ex Corde Eclesia, considera esencial para el ejercicio de la pastoral universitaria adelantar su labor en los siguientes términos:

Ofrecerán oportunidades a los miembros católicos de la Comunidad para asimilar en su vida la doctrina y la práctica católicas. Se les animará a participar en la celebración de los sacramentos, especialmente del sacramento de la Eucaristía, 
como el más perfecto acto del culto comunitario. Aquellas comunidades académicas que tienen en su seno una importante presencia de personas pertenecientes a diferentes Iglesias, Comunidades eclesiales o religiones, respetarán sus respectivas iniciativas de reflexión y oración en la salvaguardia de su credo (1990, pág. 41).

Desarrollando el sentido de la pastoral universitaria esta debe contribuir entre otras cosas a que los estudiantes puedan cumplir con sus compromisos bautismales, es decir, participar en la vida de la iglesia, en la vida sacramental, en el matrimonio, en la vida familiar y en la promoción vocacional.

Finalmente el desarrollo de las actividades de pastoral universitaria se constituye en un deber y una responsabilidad misional de la iglesia al servicio de la investigación, la enseñanza y la proyección social.

\subsection{En el Consejo Pontificio para la Cultura, según el documento "Para una Pastoral de la Cultura".}

El Consejo Pontificio para la cultura en documento del 23 mayo de 1999, establece las bases de lo que podría ser el desarrollo de la pastoral universitaria al interior de la cultura. Entendiendo que la pastoral en general debe ponerse en el 
contexto de la cultura; para cumplir el mandato evangélico de proclamar el evangelio a todos los pueblos del mundo.

Ahora bien, para lograr este cometido la cultura no se debe entender como el aprendizaje de buenos modales, o como el cultivo académico de los seres humanos para convertirlos en virtuosos; entendido como simple saber y conocer, sino que encierra algo más profundo. Precisamente por lo limitado de éste concepto el Consejo Pontificio acudió a una fuente más generosa que contribuya a la formación del ser humano como persona íntegra. Gaudium et Spes, en el año 1965 había precisado el concepto de cultura. En esta definición de carácter descriptivo se sostiene que todas las sociedades son productoras de cultura. La cultura se corresponde con el órgano que bascula la transmisión de los saberes fundantes al interior de una sociedad de padres a hijos, de una generación a otra, a través de procesos vividos de forma espontánea y aceptados como necesarios para la convivencia social. La definición se establece en los siguientes términos:

Con la palabra cultura se indica, en sentido general, todo aquello con lo que el hombre afina y desarrolla sus innumerables cualidades espirituales y corporales, procura someter el mismo orbe terrestre con su conocimiento y trabajo; hace más humana la vida social, tanto en la familia como en toda la sociedad civil, mediante el progreso de las costumbres e instituciones; finalmente, a través del tiempo expresa, comunica y conserva en sus obras 
grandes experiencias espirituales y aspiraciones para que sirvan de provecho a muchos, e incluso a todo el género humano. (Vaticano, 1966, pág. n 53)

Así las cosas existe una relación de proporcionalidad entre los campos de la cultura y los lugares en los que la pastoral podrá cumplir el mandato evangélico: "Y les dijo: Id por todo el mundo y predicad el evangelio a toda criatura" Marcos 16:15. De tal forma que la presencia de la pastoral en general se hace necesaria en la política, la economía, el derecho, artes, moral, costumbre y en palabras de Ernest Burnet Taylor, en cualquier otra capacidad adquirida por el hombre como miembro de la sociedad; incluida la Universidad en razón de la responsabilidad social y cultural que le compete en la transmisión de los saberes, la fe, la investigación y la docencia.

Es indudable que a la universidad le cabe una responsabilidad superior por ser la llamada a dar cuenta de lo propiamente humano y de la verdad que sólo se logra a través de la cultura en consonancia con el mandato dado por la constitución conciliar de contribuir en medio de la cultura a la edificación del mundo en la verdad y la justicia. Pero no se trata de una verdad que se baste a sí misma, sino que exige la cooperación entre el dato racional y el dato revelado, buscando el equilibrio y evitando los peligros de exclusión mutua en detrimento de la dimensión trascendente de la persona humana. 
La problemática de una pastoral de la cultura se relaciona con dos realidades que merecen atención la primera: el insertar la fe en las culturas y la segunda devolver la fe a un mundo descristianizado; pero que se autoproclama cristiano, tan sólo por razones culturales. Ahora bien, ante las dos dificultades ya señaladas cuál será la función de una pastoral de la cultura? La respuesta será de carácter antropológico teleológico: "consiste en restituirlo a su plenitud de criatura « a imagen y semejanza de Dios » $(G n 1,26)$, sustrayéndolo a la tentación antropocéntrica de considerarse independiente del Creador". (CPPC, 1999, pág. 6). Sin embargo, aunque el fenómeno de la cultura es universal; cada cultura es concreta y se halla atravesada por elementos que la identifican y la hacen distinta de los demás como: patrones culturales, valores, e instituciones culturales; ello no significa que se encuentre cerrada a las semillas del verbo, presentes de forma latentes en el corazón de toda cultura. Tales semillas implantadas por el Verbo Divino están listas a germinar, crecer y dar frutos por el testimonio de fe de los discípulos de Cristo. De otra parte, la pastoral de la cultura tiene que redoblar esfuerzos para revivificar el espíritu cristiano al interior de la cultura cristiana, lo que exige un replanteamiento, de la forma en que se lleva el mensaje, es decir, el compromiso con una nueva evangelización e inculturación.

La pastoral de la cultura al evangelizar, lleva la Buena Nueva, a todos los ámbitos de la sociedad humana con el propósito de renovar la cultura desde dentro ofreciendo al género humano la posibilidad de conservar lo perenne de la 
naturaleza humana, la unión entre Dios y los hombres, a pesar de la diversidad cultural, luchando contra los antivalores y potenciando las semillas del verbo dado que al interior de la cultura se pueden dar situaciones en contra de la dignidad del ser humano, que necesitan la presencia de lo ético cristiano.

La transmisión del mensaje cristiano de la irrupción de Dios Padre, en la historia humana, en la persona del Hijo y la donación de la presencia del Espíritu Santo exigen un altísimo grado de responsabilidad a la familia cristiana para presentar la Buena Nueva a los hombres del tiempo presente y futuro, desde una perspectiva intercultural abierta al dialogo y no desde un frio multiculturalismo atento de la diferencias. Ahora bien, cabría preguntar a quién corresponde la responsabilidad del trabajo de inculturación. Santo Tomás de Aquino, asigna a la familia la tarea de nutrir, educar y llevar a la prole hasta el estado perfecto de hombre en cuanto hombre, es decir, al estado de virtud. Es claro que se trata de una empresa cultural que transmite saberes de una generación a otra asignando a la educación un lugar central. De otra parte, el carisma Dominicano a diferencia de otras órdenes mendicantes asigno un lugar central a la formación intelectual confiriendo un especial cuidado a este ministerio que se desarrolla al interior de la cultura y que no es competencia exclusiva de las familias sino de toda la sociedad, en especial de la universidad. 
El reto de la pastoral de la cultura consiste finalmente en "proclamar el Evangelio a los niños y a los jóvenes desde la escuela hasta la universidad" (CPPC, 1999) a través de una evangelización inculturada que sea capaz de presentar de manera renovada el mensaje cristiano, mediante el testimonio de vida desde la novedad del evangelio.

\section{Referencias:}

Barrado J. (1993). Los Dominicos en el nuevo mundo siglos XVIII-XIX. Ed. San Sebastián Salamanca.

Carro, V. (1946). Santo Domingo de Guzmán, Fundador de la primera Orden universitaria, Apostólica y Misionera. Ciencia Tomista, 5-329.

Concilio Vaticano II (1991); Constitución Gaudium et spes, Biblioteca de autores cristianos.

Concilio Vaticano II (1991); Constitución Lumen Gentium, Biblioteca de autores cristianos. 
Concilio Vaticano II (1991); Decreto Apostolicam Actuositatem, Biblioteca de autores cristianos.

Concilio Vaticano II. Declaración Sacrosanctum Concilium. Biblioteca de autores Cristianos.

Díaz Camacho, P. J. (1993). La idea dominicana de universidad. Actas del IV Congreso Internacional Los Dominicos y el Nuevo Mundo (págs. 579-591). Bogotá: San Esteban de Salamanca.

Fernández A. (1996). Santo Tomás de Aquino, arquitecto de la vida universitaria. El profesor ideal en la Paideia tomista. Ed. Universidad San Pablo CEU.

Galmes, L., \& Gomez, V. (1987). Santo Domingo de Guzmán. Fuentes para su conocimiento. Madrid: Biblioteca de Autores Cristianos.

Gilbert, Maurice. Expectativas e instancias en exégesis después del Vaticano II. En Vaticano II: Balance y perspectivas. Sígueme, Salamanca.

Juan XXIII (1962): Discurso de inauguración del Concilio.

Latourelle, René (1989): Vaticano II: Balance y perspectivas. Sígueme, Salamanca. 
Napole, G. (2009). El estudio en el carisma dominicano. Buenos Aires : Convento San José.

Pinto de Oliveira, C. J. (1983). Los Estudios en la Orden Dominicana. Bogotá: Biblioteca Dominicana No. 15

Schillebeeckx E. (1969). El mundo y la iglesia. Ed. Sígueme Salamanca.

Consejo Pontificio para la Cultura. (2004). Documento final de la Asamblea Plenaria del Consejo Pontificio para la Cultura ¿Dónde está tu dios? La fe cristiana ante la increencia religiosa: Documentos y Publicaciones: Consejo Pontificio para la Cultura. Recuperado el 13 de julio de 2011, de http://www.vatican.va/roman curia/pontifical councils/cultr/documents/rc pc cultr doc 20040313 where-is-your-god sp.html

Consejo Pontificio para la Cultura. (23 de mayo de 1999). Para una Pastoral de la Cultura: Documentos y Publicaciones: Consejo Pontificio para la Cultura. Recuperado el 13 de julio de 2011, de http://www.vatican.va/roman curia/pontifical councils/cultr/documents/rc pc pc-cultr doc 03061999 pastoral sp.html

Consejo Pontificio para la Cultura. (22 de mayo de 1994). Presencia de la Iglesia en la Universidad y en la Cultura Universitaria: Documentos y Publicaciones: Consejo Pontificio para la Cultura. Recuperado el 13 de julio 
de

2011,

de

http://www.vatican.va/roman curia/pontifical councils/cultr/documents/rc pc cultr doc 22051994 presence sp.html

Departamento Pastoral para la Evangelización de la Cultura y la Educación, Conferencia Episcopal de Colombia. (2005). Programas y Objetivos de la Sección Universidades: Departamento Pastoral para la Evangelización de la Cultura y la Educación: Conferencia Episcopal de Colombia. Recuperado el 13 de julio de 2011, de http://www.cec.org.co/index.shtml?apc=db1;;4800;$\& m=b \& e=4800 \&$ als $[$ idsec $]=02$

Departamento Pastoral para la Evangelización de la Cultura y la Educación, Conferencia Episcopal de Colombia. (2005). Breve Historia del Departamento: Departamento Pastoral para la Evangelización de la Cultura y la Educación: Conferencia Episcopal de Colombia. Recuperado el 13 de julio de 2011, de http://www.cec.org.co/index.shtml?apc=d1- ;;22662$\underline{22662 \& \mathrm{~m}=\mathrm{b} \& \mathrm{e}=4800 \& \text { als }[\mathrm{idsec}]=01}$

JuanPabloll. (30 de diciembre de 1988). vaticano: pontífices: Juan Pablo II: exhortaciones. Recuperado el 15 de septiembre de 2011, de http://www.vatican.va/holy father/john paul ii/apost exhortations/document s/hf jp-ii exh 30121988 christifideles-laici sp.html 
PabloVI. (8 de diciembre de 1975). vaticano: Pablo VI: exhortaciones apostólicas. Recuperado el 15 de septiembre de 2011, de http://www.vatican.va/holy father/paul vi/apost exhortations/documents/hf p-vi exh 19751208 evangelii-nuntiandi sp.html

Constitución Apostólica del Sumo Pontífice Juan Pablo II sobre las universidades católicas EX CORDE ECCLESIA. Recuperado el 19 de septiembre de 2011. http://www.vatican.va/holy father/john paul ii/apost constitutions/document $\underline{\text { s/hf jp-ii apc } 15081990 \text { ex-corde-ecclesiae sp.html }}$ 